\author{
Korczyński \\ Mgr \\ Uniwersytet Wrocławski \\ (doktorant) \\ karol.korczynski@uwr.edu.pl
}

DOI: 10.35117/A_ENG_19_04_03

\title{
Spatial accessibility to public transport in a medium sized city using the example of Sanok
}

\begin{abstract}
The aim of the study is to assess the spatial accessibility of public transport within a medium sized city using the example of Sanok. In particular, the focus was on pedestrian access to bus stops, especially in terms of the distribution of housing and population, as well as the frequency of trips. In addition, an additional objective is to determine the feasibility of using data sources available in Poland, such as the Topographical Objects Database, Open Street Map or the 2011 Census, to study the accessibility of public transport in medium-sized cities. The results should form the basis for further benchmarking of such cities. The analysis showed that the vast majority of the population of Sanok has access to public transport from their places of residence, but the number of available courses varies considerably from one area to another and is divided into working days, Saturdays and Sundays. In most cases, the number of courses serving stops corresponds to the characteristics of their accessibility areas in terms of population or location of important destinations. It also identified built-up areas with relatively low accessibility or lacking good accessibility to public transport. The data sources used in the study, available throughout the whole country, as well as the procedures applied for their preparation and presentation allow for more extensive comparative research in the future in the area of many cities.
\end{abstract}

Keywords: Spatial accessibility; Urban transport; Middle-sized cities

\section{Introduction}

Accessibility to public transport, including urban transport, is a multifaceted and very important research and application problem. It results from a significant increase in the mobility of the inhabitants connected with a number of socio-economic phenomena, e.g. increase in social aspirations, development of suburban zones, changes in the location patterns of companies resulting in a larger scale of commuting to work, development of large-format trade, etc. It also results from a significant increase in the mobility of inhabitants connected with a number of social and economic phenomena, e.g. increase in social aspirations, development of suburban zones, changes in the location patterns of companies resulting in a greater scale of commuting to work, development of large-format trade, etc. It is also caused by an imbalance between transport needs and the ability to meet them. Accessibility of public transport is an important condition for preventing transport exclusion and for effective urban development [5]. Well-organised public transport contributes to the reduction of road network load and shortens travel time [38][18]. The works conducted so far have focused mainly on the research of large cities or metropolitan systems, e.g. in the field of transport policy [44], quality of passenger service [4][43] or transport accessibility [11][38]. This is natural given the scale and complexity of the problems faced by public transport there. However, this results in a certain cognitive gap in the identification of the most important public transport patterns in medium-sized cities. This is particularly true in Poland, where research in these cities is relatively scarce [29][33]. Due to their much smaller spatial scale, functional and 
spatial structures specific in a number of cases, the volume of traffic or the different financial possibilities of local authorities, the research approach to the analysis of medium-sized cities should not be the result of a simple transfer of the approach typical of large units. This poses a number of new challenges in terms of the research approach and how to take into account the individual character of the examined cities.

The aim of the study is to assess the spatial accessibility of public transport within a medium sized city using the example of Sanok. The research was conducted as at 1 January 2019. In particular, the focus was on pedestrian access to bus stops, especially in terms of the distribution of housing and population, as well as the frequency of trips. In addition, an additional objective is to determine the feasibility of using data sources available in Poland, such as the Topographical Objects Database, Open Street Map, or the 2011 Census, to study the availability of public transport in medium-sized cities. The results should form the basis for further benchmarking of such cities.

The simplest and most commonly used definition of a medium-sized city in Poland is that it is inhabited by 20 to 100 thousand people [26][23][13]. Residents of such middle-sized cities constitute almost $1 / 3$ of the population of cities in Poland and about $1 / 5$ of the total population of the country. The city of Sanok, with a population of less than 38 thousand, differs slightly from the average value (41 801) and the median value (37 144) of the population of Polish cities included in the category of medium-sized cities [1]. From the point of view of size, they can therefore be considered as typical representatives of this category. Moreover, the location in a certain distance from the functional areas of the largest metropolitan centres and the organisational independence of public urban transport make it possible to carry out research in the context of the local authorities' own transport policy.

\section{Theoretical aspects of public transport research in the spatial aspect}

Research on medium-sized cities is undertaken relatively rarely in the literature on the subject. As indicated by Runge [26] and Panecka-Niepsuj [23], this is mainly due to better access to data for large cities and the ease of researching small cities. Panecka-Niepsuj [23] additionally mentions the authors' tendency to focus on extreme units in terms of size (i.e. large and small). Moreover, in large urban areas, new phenomena and processes taking place in the socio-economic space can be observed most quickly and easily (e.g. the concept of creative cities [8], new urbanism [39], etc.) and, due to their scale, the complexity of their determinants. The above observation, as mentioned in the introduction, also concerns issues related to urban public transport research, conducted mainly in large cities [11][37][14][16].

Studies related to the issue of public transport travel most often concern its individual stages. As a rule, it is distinguished by [11]:

1. to get to the starting point,

2. waiting for a public transport vehicle,

3. the passage,

4. optional - time of change (understood as the time of changing to another stop and waiting for the next vehicle),

5. optionally - another ride,

6. to get from the bus stop to the destination.

7.

This work focuses mainly on the first two and the last of these stages.

A significant problem with research is the question of determining the average time passengers spend on traveling and using public transport services. Spirin [31] proposes the following formula for its calculation:

where:

$$
t=2 t_{p}+\left(t_{o}+t_{j}\right) \cdot W_{p r}
$$


$t_{p}$ - time of transition between the stop and the starting point (target),

$t_{o}$ - waiting time for the means of transport,

$W_{p r}$ - transfer coefficient (1+ average number of transfers).

It also points out that the variation in this value is much more important on intra-urban and suburban routes than on longer distances, mainly due to the regularity in the use of such routes by individual passengers.

A comprehensive discussion of the issues of transport accessibility in the context of the Polish territory was made by Rosik et al [25]. It draws attention to the multi-faceted nature of this concept, which makes it difficult to construct a correct definition of it. At the same time, it takes as a basis for research the definition proposed by Vickerman [36], according to which transport accessibility is synonymous with minimizing the costs of travelling to selected destinations. Olszewski et al. [22] define accessibility to public transport as the accessibility of public transport and the accessibility of public transport to the destination. It seems that such a formulation accurately reflects the multi-faceted nature of this issue and indicates that it should be considered in terms of its division into individual stages of travel.

It is important to determine how to measure pedestrian access to public transport stops and to adopt limit values that determine the area for which a given stop will be considered accessible. The concept of time availability (expressed in minutes) or spatial availability (expressed in metres) may be used. There are no generally accepted accessibility limits in the literature so far and therefore they differ significantly from one study to another and are the result of individual assumptions such as walking speed, age of passengers, nature of settlements or type of public transport. For example, good accessibility limits of $300 \mathrm{~m}$ or 3 $\min 45 \mathrm{~s}$ [11], $400 \mathrm{~m}$ or $5 \mathrm{~min}$ [21][34][41], $640 \mathrm{~m}$ [12] as well as $800 \mathrm{~m}$ or $10 \mathrm{~min}$ [27] apply to urban bus transport. The most commonly used threshold is $400 \mathrm{~m}$ or 5 minutes [21][34][41] respectively. It is also used in this work. Availability expressed in metres and minutes can often be used interchangeably, depending on the needs, according to the walking speed assumed in the study. In Gadzinski's work [11], for example, it amounts to $4.8 \mathrm{~km} / \mathrm{h}$. In this context, Olszewski et al. takes an interesting approach. [22], proposing a close link between the time of arrival at the stop (and consequently the extent of good accessibility) and the average time of waiting for a vehicle, related to the frequency of journeys. The advantage of such an assumption is that the basic and necessary elements of the journey are combined without the use of vehicles. It should be noted, however, that the average frequency of the bus stops only partially determines the waiting time, as it ultimately depends on the desired destination. At the same time, the importance of waiting time should systematically decrease with the dissemination of Internet services supporting travel planning. Moreover, waiting for a vehicle is probably much less onerous for passengers than getting to a stop involving a physical effort.

By defining the above optimal and limit values for accessibility to stops, it is possible to determine the areas of accessibility to public transport on the basis of these values. A number of different approaches are used. Olszewski et al. [22], Tsiotas and others. [35] and Yuen and others. [42] use in this case the liquidator, i.e. districts whose means are bus stops and whose radiuses are the adopted limit values of good spatial accessibility. Saghapour and others. [27] and Wiśniewski [37][38] use isochronos in their research, i.e. lines of equal time distance from stops created on the basis of the assumed value of time availability and the existing network of roads adapted to pedestrian traffic in a given area. Both approaches have their limitations. In the case of the liquidator, the quite obvious fact that the road to or from the bus stop is not usually in a straight line is omitted, which leads to overstating the area of accessibility areas. On the other hand, isochronisation is technically more complicated and requires the use of additional (in case of pedestrian availability very accurate) spatial data. 
While basic spatial data is sufficient to properly determine the isochronous system on a larger scale, for example for road or rail transport [15][32][32], the isochrones determined for stops must take into account all realistically accessible pedestrian routes. In a number of cases this can be problematic, especially if they are not included in any official planning documentation and are connected e.g. with the phenomenon of so-called desire paths [30]. Therefore, it can be assumed that there is a risk of underdevelopment of accessibility areas with respect to isochronisation, although the scale of this underdevelopment is much higher in areas with lower building density, such as suburbs. Loose [19] and Gadziński [11], bearing in mind the above mentioned limitations, propose a solution that attempts to find a compromise between the approaches based on euthanasia and iso protection. It consists in modification of the equidistants radius by the so-called distance extension coefficient, understood as the average of quotients of the actual distance covered and the Euclidean distance between pairs of selected points in the studied area. This approach, although more precise than the simple application of e-removal, is still quite a simplification. The conducted studies comparing the reliability of calculation of isochron and eliquidator when determining the availability of public transport stops show that isochronisation is justified, provided that available data allow it [28][9][32].

Another key issue in identifying areas of accessibility to stops is to properly define the characteristics of these areas. This applies in particular to the issue of the number of people living within the bus stop area. Wiśniewski [37] and Borowska-Stefańska and Wiśniewski [3] carried out research based on the number of people registered in particular buildings in Łódź. However, they are unique because it is generally impossible or very expensive to obtain the relevant data. Therefore, the most common approach in the literature is to estimate the population on the basis of data for the smallest possible areas for which they are available. The estimation procedures used generally consist in allocating population values to areas of availability in proportion to the areas of the spatial units of which they are composed for which statistical data are available. This approach is used, for example, by Saghapour et al. [27] for Melbourne based on Statistical Areas level 1 (SA1) or by Gadzinski [11], based on data for housing estate councils in Poznań. The main disadvantage of this approach is that it assumes an even distribution of population across the different areas, which in practice is very rarely observed and can lead to significant inaccuracies in estimation. Therefore, other, more precise methods of determining the distribution of the population are used. Biba and others [2] use for this purpose dwelling units and attribute to them the population in proportion to the proportion of the census block dwellings on the parcel. It seems that similar results can be achieved by calculations based on the layout of residential buildings.

Determining the population living within the reach of each stop determines whether it is sufficient for the resulting transport needs to justify the use of urban transport for the purpose of serving the area. Dittmar and Ohland [6] and Downs [7] refer to the assumption frequently used in the United States that the minimum building density of a traffic service area should be 7 housing units per square mile $(2.7 / \mathrm{km} 2)$. Downs also gives an alternative index of 4200 people per square mile (1621 people per km2). It should be remembered, however, that the specificity of American cities, especially in the context of urban transport, differs significantly from the Polish or European conditions. The above values should therefore be treated with some caution.

One of the most extensive and detailed works focusing on the functioning of urban transport in medium-sized cities in Poland is the assessment of the demand for urban transport services in Krosno and neighbouring communes, prepared by Trako, together with the concept of supply optimisation [33]. The paper contains the results of detailed measurements of the number of passengers depending on the line and bus stop in the hourly system. The effect of the conducted research is to propose specific changes in the course and frequency of 
courses of urban transport lines. This type of shots have undoubtedly a very large application potential.

\section{Test method}

One of the basic difficulties associated with conducting research in relation to medium-sized cities is generally more difficult to access data than in large cities [26][23]. This also applies to public transport research. Moreover, due to the possibility of making comparative analyses, it is justified to use data that are not unique and available to many cities. Therefore, the sources used in the paper are mainly sources covering the whole of Poland and created on the basis of uniform standards.

The Topographic Objects Database (BDOT) has been used to determine the location of bus stops and has been validated on the basis of Open Street Map data, satellite images and Google Street View.

Data on the number of routes of particular lines on particular days of the week were assigned as attributes to spatial data on bus stops on the basis of information on timetables and routes of lines published by Zakład Miejskiej Komunikacji Samochodowej in Sanok.

The basic software used for the analysis is ArcMap 10.6.1. for spatial data processing and Microsoft Office Excel for database collection and processing.

Based on Open Street Map road and walkway data, ArcMap 10.6.1. generated isochrones of 5 and 10 minutes of walking to stops with the help of Network Analyst, which are the boundaries of areas with good and minimum accessibility (assuming a walking speed of $4.8 \mathrm{~km} / \mathrm{h}$ ). Then you processed the generated layer so that the areas common to two or more isochronous areas represent their total or maximum values. It should be noted that although Open Street Map is not an official database, it contains the most extensive and up-todate resource of roads and pedestrian lanes and seems to be the most appropriate data source to create an isochronous pedestrian accessibility. Open Street Map is increasingly used in scientific research [20][17][10][24].

Due to the lack of sufficiently up-to-date and accurate data on the distribution of population in the city space at work, the estimation procedure was carried out on the basis of BDOT data based on the location of residential buildings and taking into account their area, number of floors and utility function. The total population of the city was divided among the individual residential buildings in proportion to their total area, understood as the quotient of the building area and the number of floors of the building. It has been taken into account that the area per capita in multi-family buildings is usually smaller than in single-family buildings. The difference was estimated on the basis of data on the population in the census districts of Sanok according to the Census 2011 and the total residential area in these districts. The accuracy of the estimation procedure was also checked - the value of the Pearson correlation coefficient between the actual (determined according to the Census 2011) and the estimated (based on the distribution of residential buildings) population in 174 census districts in Sanok in 2011 was 0.864 . This indicates that the adopted procedure (naturally with some caution) may be used in local studies, especially in the absence of other data sources.

Information about the buildings was obtained from BDOT. It should be noted that this source includes the state of 2012 , so potentially it may be partly outdated. There are at least two alternative databases containing this type of data and with a much higher level of updating: Open Street Map and Land and Building Registry. In the first case, however, there is no information in the database about the functional function of the buildings and the number of their floors, which is necessary for the procedure of estimating the population. In the latter case, on the other hand, the database can only be obtained through an administrative procedure and the form made available requires considerable and time-consuming processing. It should be taken into account that, according to GUS data, in the years 2012-2017 (i.e. since 
the establishment of BDOT) only 180 residential buildings (205 apartments) were put into use in Sanok, including only one multi-family building [1]. Newly constructed buildings do not form dense clusters, but they are fairly evenly distributed over previously built-up areas. It can therefore be assumed that the degree of obsolescence of BDOT data on residential information in Sanok is very low and should not have a significant impact on the survey results.

\section{Accessibility to public transport in Sanok}

Sanok lies in the San River Valley, in the Sanok Valley, on the border of the SanockoTurczańskie Mountains and the Bukowskie Foothills, which are parts of the Eastern and Western Carpathians respectively. It is connected with the presence of two main spatial and communication barriers. The San River restricts the development of buildings, which are concentrated on its left bank. The hills in the northeast and southwest of the city cause that it has a slightly elongated shape in the direction of the NW-SE, which also runs the main communication axis of the city. It consists of national roads No. 28 and 84 leading to Przemyśl, Krosno and Ustrzyki Dolne. There is also a railway line running through the city.

Municipal Motor Transport in Sanok currently operates 107 stops within the administrative boundaries of the city. There are 11 lines in operation on working days, 9 on Saturdays and 8 on Sundays. Courses are held from 5:15 to 23:40, from 5:32 to 22:20 and from 6:05 to 22:40 respectively. One-way and one-way travel within the city limits takes from 10 to 31 minutes. The fleet consists entirely of buses of the brand Autosan, whose factory is located in the city.

The conducted research shows that two areas with good accessibility to bus stops with the highest number of trips can be distinguished, both on working days (Fig. 1.), Saturdays (Fig. 2.) and Sundays (Fig. 3.). The first of them, of a strongly elongated shape, stretches from the Central Cemetery (1) in the northwest, through the southern part of the Old Town (2), the railway and bus station (3), to the industrial district of Posada (4) in the southeast. There are all bus lines except one, the peak one (with only three courses on working days). The second area with good access to a large number of courses includes the largest residential complex in Sanok, located in the northwest of the central part of the city and bounded to the north and east by the San River. There is also a bus depot (5). A relatively large number of courses are also characterized by stops located along national roads leading through the city. This is partly due to the fact that public transport also serves the areas of the neighbouring rural commune of Sanok and the urban-rural commune of Zagórz. 


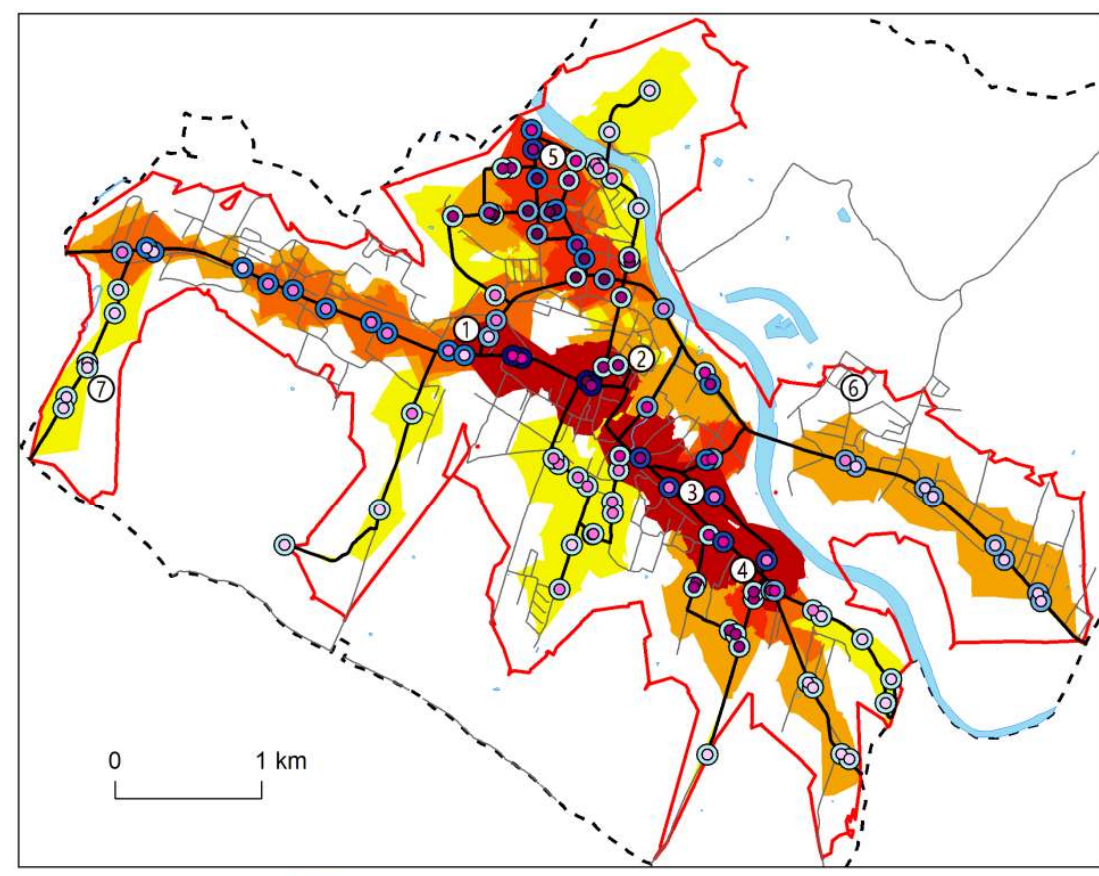

wody powierzchniowe
(2) przystanki autobusowe

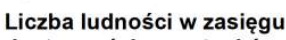

dostępności przystanków

- powyżej 3000

- $1800-3000$

- $1000-1800$

- $300-1000$

○ do 300

Liczba linii obsługujących

przystanki

9-10

$7-8$

5-6

O $3-4$

O 1 - 2

Obszary dostępności piesze

do przystanków do $5 \mathrm{~min}$.

liczba kursów w dni robocze

$90-115$

$65-89$

$45-64$

$25-44$

$1-24$

obszary dostępności

$\square$ pieszej do przystanków do $10 \mathrm{~min}$.

oznaczenia miejsc

(1) przywoływanych w tekście

1. Spatial accessibility, number of lines and number of courses of Urban Motor Transport in Sanok (within the limits of the city of Sanok on working days, as of December 12, 2018). Source: Own calculations based on data obtained

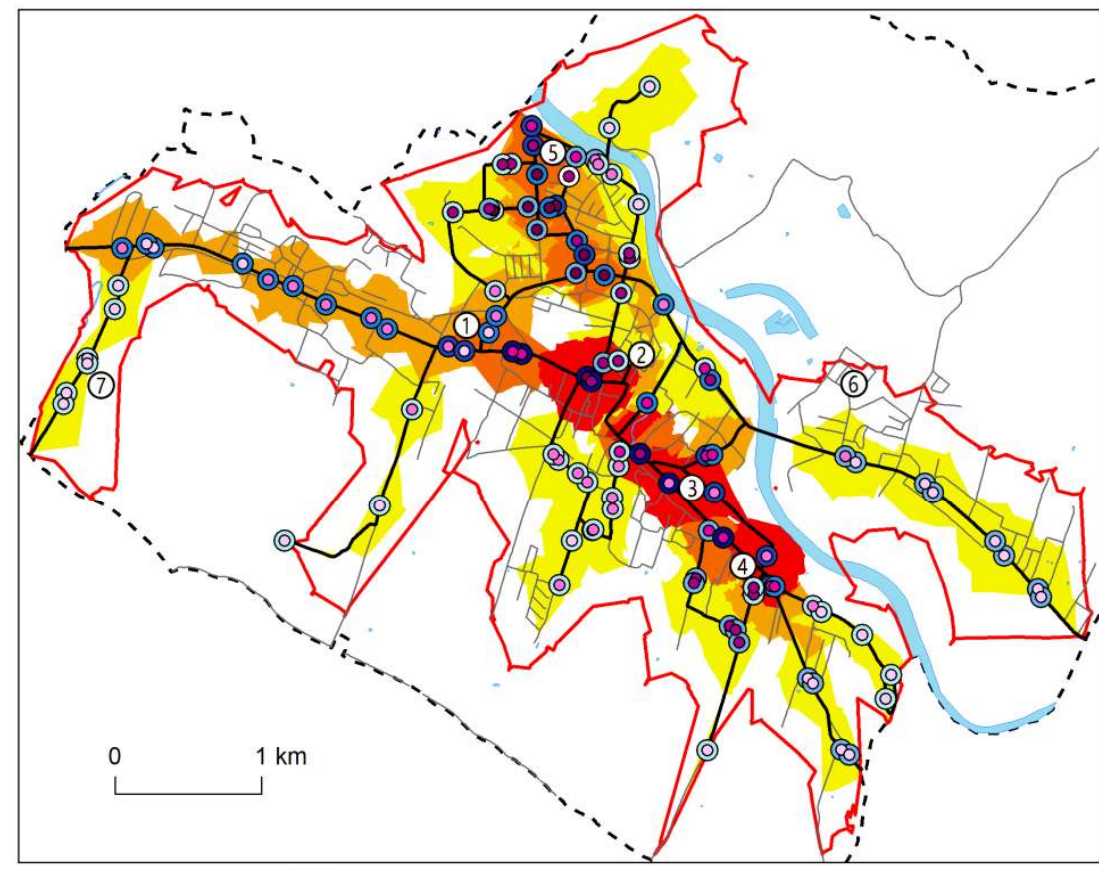

I_- $\mathbf{-}$ granica miasta $\square$ wody powierzchniowe $\square$ trasy linii MKS Sanok $\quad$ pozostale drogi
(2) przystanki autobusowe Liczba ludności w zasięgu dostępności przystanków

- powyżej 3000

- $1800-3000$

- $1000-1800$

- $300-1000$

○ do 300

Liczba linii obsługujących przystank

7-9

$5-6$

3-4

○ 2

O 1

Obszary dostępności piesze do przystanków do 5 min. liczba kursów w soboty

$65-74$

$45-64$

$25-44$

$2-24$

obszary dostepności

pieszej do przystanków do $10 \mathrm{~min}$.

oznaczenia miejsc w tekście

2. Spatial accessibility, number of lines and number of courses of Urban Motor Transport in Sanok (within the limits of the city of Sanok on Saturdays, as of December 12, 2018) Source: Own calculations based on data obtained 


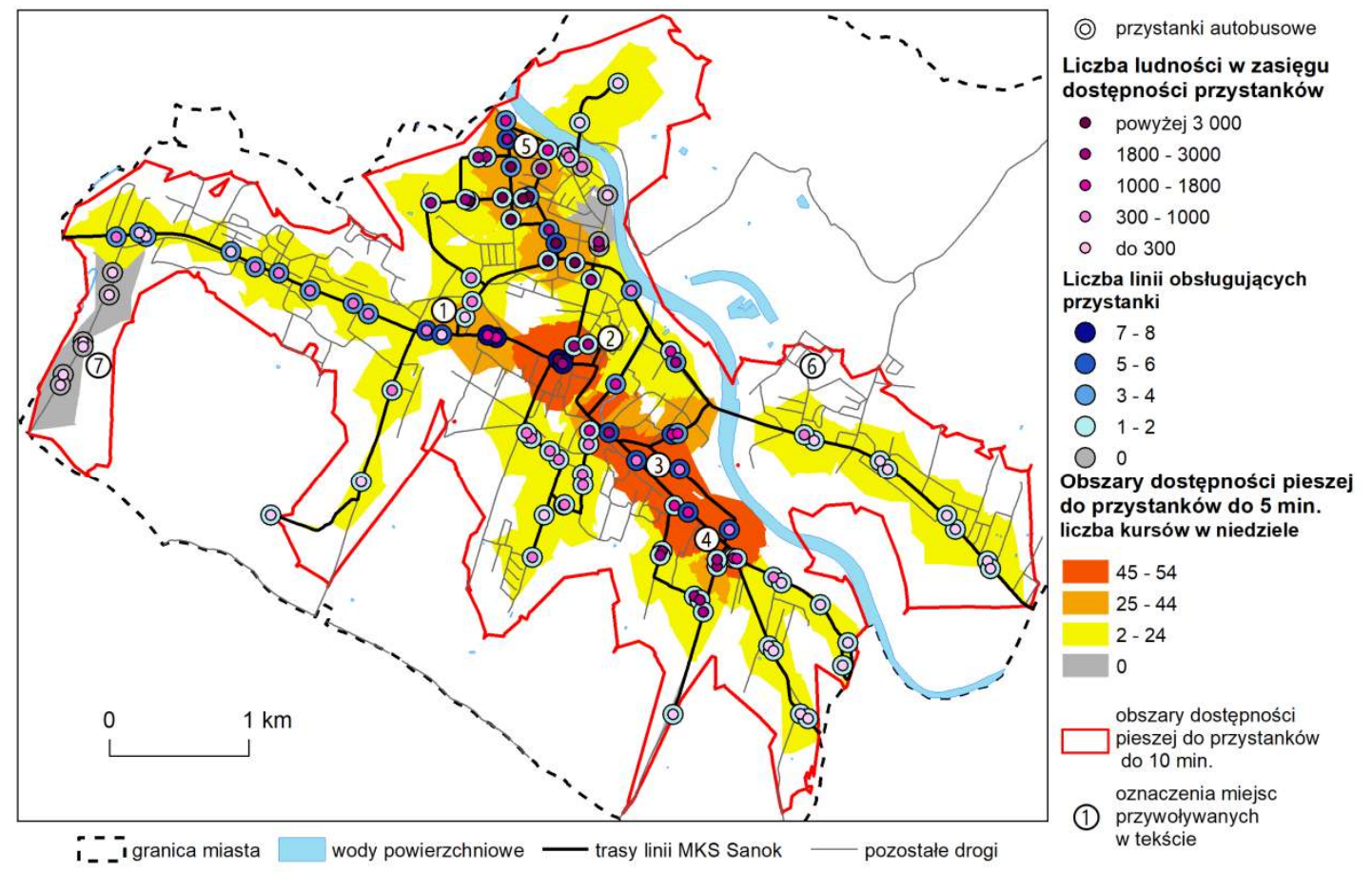

3. Spatial accessibility, number of lines and number of courses of Urban Motor Transport in Sanok (within the limits of the city of Sanok on Sundays, as of December 12, 2018)

Source: Own calculations based on data obtained

It should be emphasized that some stops in the accessibility zones to which many inhabitants live are characterised by a relatively small number of courses (Fig. 1-3.). In some cases, this can be explained by the location of a number of buildings in areas of good accessibility simultaneously to several stops, only some of which are served by a large number of courses. It is also worth noting the stops with a relatively large number of lines and courses, in the vicinity of which there are not many people living. They are located in particular in the southleastern part of the most intensive transport service area. This is probably due to the largest concentration of industrial plants with a significant number of employees [40], as well as railway and bus stations. Due to the low frequency of train services and the non-use of the bus station by all long-distance bus operators operating in Sanok, the latter is likely to be of lesser importance. There are also areas with relatively low availability of courses in relation to housing development. Such a state of affairs occurs, among others, in the western part of the largest housing estate, in the north of the central part of the city and in the south of the district of Posada. Residents in these areas usually have access to more courses within a 10-minute walking distance. There are also areas with buildings that do not have good access to any bus stop, and therefore are beyond the reach of a five-minute walk. First of all, you should pay attention to the complex of multi-family buildings in the northeastern part of the city, on the right bank of the San River (6). Some of the existing buildings are not even within 10 minutes of the bus stop. Therefore, it is an area with definitely insufficient accessibility, which indicates the need to develop urban transport in this part of the city. A certain problem is the existence of a zone of residence in this area, through which, as a rule, public transport lines should not run. Perhaps meeting the transport needs of the inhabitants would require changes in the traffic organisation. 
Despite large differences in the number of courses on working days (Figures $\mathbf{1}$ and $\mathbf{4}$ ), Saturdays (Figures 2 and 4) and Sundays (Figures 3 and 4) on the whole city scale, the relative differences between individual areas of accessibility on specific days do not change significantly. It is worth noting that the accessibility area is reduced on Sundays, when 11 stops in two different parts of the city are not serviced at all (Fig. 3.). The lack of accessibility is then observed especially in the westernmost part of the city (7) However, it is a relatively sparsely populated area with a predominance of industrial buildings, which further increases the importance of access to public transport on working days in relation to Saturdays and Sundays. On the other hand, the identified lack of accessibility also applies to the village of Sanoczek to the south-west of the city, which on Sundays has no public transport connection with Sanok.

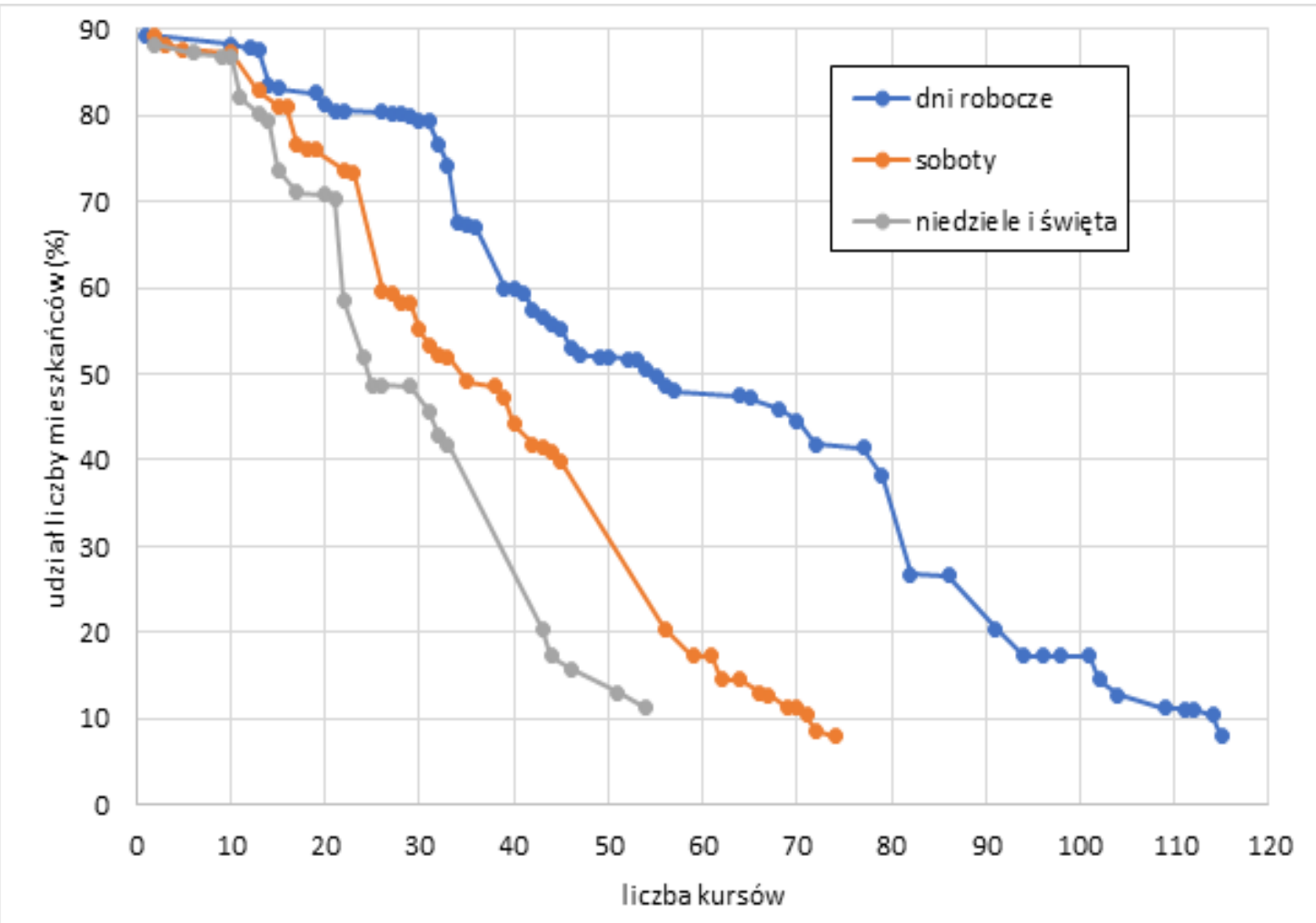

4. Share of the number of residents of Sanok living within the range of good spatial accessibility to a specified number of courses (as at 12 December 2018)

Source: Own calculations based on data obtained

The mere fact that there is good accessibility to a bus stop is not enough to conclude that there is good accessibility to public transport, because bus stops differ significantly in the number of lines and routes they serve (Fig. 1-3.). In order to take these conditions into account, a graph showing the share of city residents with good access to a specific number of courses was proposed (Fig. 4.). It allows you to create profiles of accessibility to public transport and to make comparisons between different units. Despite the identified accessibility limitations, almost $90 \%$ of the city's population has good access to at least one bus stop (Figure 4). This share decreases significantly, however, if the availability of a certain number of courses is taken into account. For example, for an average frequency of running every 30 minutes, assuming that the buses run for about 18 hours a day (which is a result of the current timetable), the desired number of trips during the day would be 36. Such a frequency of runs on working days is available to about $2 / 3$, on Saturdays to less than half, and on Sundays to less than $1 / 5$ of the total number of inhabitants of the city. On the other hand, on average 
every 20 minutes, which in some studies is considered to be the limit below which passengers stop following the timetable [22], in Sanok approximately $50 \%$ of the population would have access to the trips on working days. The division into individual lines was not taken into account, which would further reduce the values obtained. Bearing in mind that all suburban fares pass through the central part of the city and that the majority of passengers move between the suburbs and the centre, it can be assumed, however, that this division is only relevant in the area of the most intensive traffic service, through which the lines running in different directions run. A simpler functional-spatial structure and transport network than large cities and a much lower frequency of trips also reduce the importance of interchanges.

\section{Summary}

The analysis showed that the vast majority of the population of Sanok has access to public transport in their places of residence, but the number of available courses varies considerably from one area to another and is divided into working days, Saturdays and Sundays. In most cases, the number of courses serving stops corresponds to the characteristics of their accessibility areas in terms of population or location of important destinations. It also identified built-up areas with relatively low accessibility or lacking good accessibility to public transport.

The data sources used in the study, available throughout the whole country, as well as the procedures applied for their preparation and presentation allow for more extensive comparative research in the future in the area of many cities. This type of research makes it possible to assess the functioning of urban transport and to indicate the rules governing it. This will allow to determine the directions of development of urban transport systems in medium-sized cities within the framework of the transport policy shaped by them, enabling optimal satisfaction of transport needs of their inhabitants.

\section{Source materials}

[1] bdl.stat.gov.pl, February 1, 2018.

[2] Biba S., Curtin K. M., Manca G. A new method for determining the population with walking access to transit. International Journal of Geographical Information Science, 2010, 24, s.347-364.

[3] Borowska-Stefańska M., Wiśniewski S. Availability of Łódź parks in the light of individual, collective and bicycle transport. Communication Review, 2018, 2, pp. 9-16.

[4] Cascetta E., Carteni A. A Quality-Based Approach to Public Transportation Planning: Theory and a Case Study. International Journal of Sustainable Transportation, 2014, 8, s.84-106.

[5] Church A., Frost M., Sullivan K. Transport and social exclusion in London. Transport Policy, 2000, 7(3), s.195-205.

[6] Dittmar H., Ohland G. The new transit town. Best practices in transit-oriented development. Island Press, 2004.

[7] Downs A. Still Stuck in Traffic: Coping with Peak-Hour Traffic Congestion. Brookings Institution Press, 2004.

[8] Florida R. L. The rise of the creative class, and how it is transforming work, leisure, community and everyday life. Basic Books, 2002.

[9] Foda M. A., Osman A.O. Using GIS for measuring transit stop accessibility considering actual pedestrian road network. Journal of Public Transportation, 2010, 13(4), s.23-40.

[10] Gadziński J., Bul R. Planning new public transport line based on accessibility criteria. Communication Review, 2017, 4, p.2-7. 
[11] Gadziński J. Assessment of the accessibility of urban transport space on the example of Poznań. Bulletin of the Institute of Socio-Economic Geography and Spatial Management, Series Regional Development and Regional Policy, 2010, 13.

[12] Gent C., Symonds G. Advances in public transport accessibility assessments for development control - a proposed methodology. Capita Symonds Ltd. Transport Consultancy, 2005.

[13] Central Statistical Office. Cities in numbers 2016. Central Statistical Office, 2018.

[14] Goliszek S., Połom M. The use of general transit feed specification (GTFS) application to identify deviations in the operation of public transport at morning peak hours on the example of Szczecin. Europa XXI, 2016, 31, s.51-60.

[15] Goliszek S. Improvement of railway accessibility of voivodship cities of Eastern Poland in the investment variant - comparative analysis. Communication Review, 2014, 8, pp. 20-23.

[16] Goliszek S. Space-time variation of accessibility to jobs by public transport - a case study of Szczecin. Europa XXI, 2017, 33, s.49-66.

[17] Hochmair H. Assessment of Bicycle Service Areas around Transit Stations. International Journal of Sustainable Transportation, 2015, 9, s.15-29.

[18] Jaskólski M., Smolarski M. Spatial development and transport accessibility of Wrocław suburbs on the example of Siechnice, Smolc and Długołęka. Communication Review, 2018, 2, pp. 4-8.

[19] Loose W. Flächennutzungsplan 2010 Freiburg - Statement on the transport impacts. Öko-Institut e.V., 2001.

[20] Maciejewski M., Piątkowski B., Walerjańczyk W. From the macroscopic model of travel demand to the 24-hour microscopic simulation of motion flow. Communication Review, 2014, 2, pp. 27-31.

[21] Murray A.T., Davis R., Stimson R.J., Ferreira L. Public Transportation Access. Transportation Research Part D: Transport and Environment, 1998, 3(5), s.319-328.

[22] Olszewski P., Dybicz T., Śleszyński P. Proposed measures of time availability in public transport. Communication Review, 2013, 12, pp. 10-17.

[23] Panecka-Niepsuj M. Spatial diversification of the economic situation of medium-sized cities in Poland. Urban Studies, 2015, 20, pp. 167-177.

[24] Transferred G., Taczanowski J. Evaluation of the transport system of the suburban commune on the example of Konopiska (Częstochowa district). Prace Komisji Geografii Komunikacji PTG, 2017, 20 (3), pp. 31-43.

[25] Rosik P., Pomianowski W., Goliszek S., Stępniak M., Kowalczyk K., Guzik R., Kołoś A., Komornicki T. Multimodal access by public transport to communes in Poland. Geographical works, 2017, 258.

[26] Runge A. Methodological problems of research of medium cities in Poland. Geographical Works, 2012, 129, pp.83-101.

[27] Saghapour T., Moridpour S., Thompson R. Public transport accessibility in metropolitan areas: A new approach incorporating population density. Journal of Transport Geography, 2016, 54, s.273-285.

[28] Salvo G., Sabatini S. A GIS approach to evaluate bus stop accessibility. Proceedings of the 16th Mini-Euro conference and 10th meeting of EWGT, 16 września 2005 roku.

[29] Sienkiewicz J., Hołyst J. Statistical analysis of 22 public transport networks in Poland. Physical Review E - Statistical, Nonlinear, and Soft Matter Physics, 2005, 72(4), 046127.

[30] Smith N., Walters P. Desire lines and defensive architecture in modern urban environments. Urban Studies, 2018, 55, s.2980-2995. 
[31] Spirin I. W. Organization and management of passenger transportation Textbook. Academy Publishing Center, 2010.

[32] Śleszyński P., Dybicz T., Olszewski P. The degree of time availability as a synthetic indicator of the level of transport service. Communication Review, 2015, 6, pp. 23-27.

[33] Trako. Wierzbicki i Wspólnicy S.J. The amount of demand for urban transport services in Krosno and in neighbouring communes comprising MOF Krosno together with the concept of optimising the supply of its services. Thracian. Wierzbicki i Wspólnicy S.J., 2016.

[34] Transport for London. Accessible bus stop guidance. Transport for London. 2006.

[35] Tsiotas D. K., Kalantzia O. S., Gavardinas I. D. Accessibility assessment of urban mobility: the case of Volos. Transportation Research Procedia, 2016, 24, s.499-506.

[36] Vickerman R. Accessibility, attraction, and potential: a review of some concepts and their use in determining mobility. Enviroment and Planning A, 1974, 6, s.675-691.

[37] Wiśniewski S. Operation of night public transport in Łódź. Communication Review, 2016, 7, pp. 4-8.

[38] Wiśniewski S. Łódź accessibility by public transport. Europe XXI, 2016, 31, pp. 61-78.

[39] www.cnu.org/who-we-are/charter-new-urbanism, February 1, 2019.

[40] www.sanok.pl/gospodarka, February 1, 2018.

[41] Yigitcanlar T., Sipe N., Evans R., Pitot M. AGIS-based land use and public transport accessibility indexing model. Australian Planner, 2007, 44(3), s.30-37.

[42] Yuen A., Martins Rocha C., Kruger E., Tennant M. Does public transportation improve the accessibility of primary dental care in São Paulo, Brazil?. Community Dentistry and Oral Epidemiology, 2018, 46, s.265-269.

[43] Zajfert M. Influence of qualitative factors of urban transport in Poland on the substitution of means of transport. Communication Review, 2018, 8, pp. 2-9.

[44] Zhu W., Chen M., Wang D., Ma D. Policy-Combination Oriented Optimization for Public Transportation Based on the Game Theory. Mathematical Problems in Engineering, 2018, 7510279. 